\title{
An overtraining-reversal effect with differential avoidance conditioning in rabbits
}

\author{
MICHAEL GABRIEL, STEVEN E. SALTWICK, GEORGE KAMPSCHAEFER \\ University of Texas, Austin, Texas 78712
}

\begin{abstract}
Two groups were formed from a large sample of rabbits used as subjects in ongoing studies of the neural correlates of discriminative avoidance conditioning and reversal. The members of one group $(\mathrm{N}=9)$ received conditioning to criterion, whereas members of the second group $(N=9)$ received conditioning to criterion followed by three sessions of overtraining. All subjects received 5 days of reversal training. The groups were matched for mean number of sessions to the acquisition criterion. The $\mathrm{CS}+$ and $\mathrm{CS}-$ were pure tones which differed in frequency, and the UCS was shock delivered through the grid floor of a rotating wheel apparatus. The response was locomotion within the wheel. The overtrained group showed a significantly greater discrimination appropriate to the reversal problem than did the nonovertrained group on Day 5 of reversal training. This result indicates that an overtraining reversal effect (ORE) occurs in the context of acoustically cued, aversively motivated discriminative avoidance behavior of rabbits.
\end{abstract}

Discrimination training beyond criterion is often associated with rapid reversal, relative to reversal following criterial training. This effect, called the overtraining reversal effect (ORE), has been reported in many studies (see reviews byMackintosh, 1974; Paul, 1965; Sperling, 1965; Sutherland \& Mackintosh, 1971). In addition, several theories of the ORE have been presented (Denny, 1970; Hall, 1974; Lovejoy, 1966; Mandler, 1968; Paul, 1965; Reid, 1953; Siegel, 1967; Sutherland \& Mackintosh, 1971). The number of theories suggests that the ORE has provoked a substantial interest, yet the generality of the ORE, defined in terms of the varieties of learning task in which it occurs, has remained unexplored. To our knowledge, the ORE has not been reported for tasks other than those involving visual or spatial discriminanda and appetitive sources of motivation. The present paper is a report of the ORE obtained with rabbits trained in differential avoidance conditioning with acoustic stimuli.

\section{METHOD}

\section{Subjects}

The subjects were 18 male albino rabbits. They were maintained on ad-lib food and water throughout the experiment. They were chosen from a larger group constituting the subject pool of ongoing studies of the neural correlates of discrimination learning (e.g., Gabriel, Miller, \& Saltwick, 1976a, b). Chronically implanted electrodes for recording neuronal electrical activity were located in three brain areas in each subject.

\section{Apparatus and Procedure}

All subjects received differential conditioning and reversal training in a wheel apparatus (Brogden \& Culler, 1936). The response to be conditioned was locomotion within the wheel sufficient to produce a rotation of at least $.96 \mathrm{~cm}$ on the cir-

This research was supported by NIMH Grant MH 2627-01 and by grants from the Spencer Foundation, the Biomedical Sciences Committee, and the University Research Institute. cumference of the wheel. The CS+ and CS- were pure tones $\left(8 \mathrm{kHz}, 1 \mathrm{kHz}, 80 \mathrm{~dB}\right.$ re $\left..0002 \mathrm{dyne} / \mathrm{cm}^{2}\right)$, and the UCS was a $1.5-\mathrm{mA}$ shock delivered through the grid floor of the apparatus. CS+ onset preceded UCS onset by 5 sec. Both stimuli were terminated by the response. A response in the presence of a CS terminated it and prevented the UCS if one was scheduled. Each subject received 120 trials/day, 60 with the CS+ and 60 with the CS-. The two stimuli occurred in a random order, with the restriction that an equal number of CS+s and CS-s occur in each 20-trial block. One subgroup $(\mathrm{N}=9)$ was given training to criterion (two consecutive sessions in which $9 / 10$ CRs to the CS+ and $9 / 10$ nonresponses to the CS- occurred in any 20-trial block). A second subgroup $(\mathrm{N}=9)$ received training to criterion plus three sessions (overtraining) beyond criterion. Following criterion attainment or overtraining, each rabbit was given five sessions of reversal training. ${ }^{1}$ Further details of the procedure are provided in previous reports (Gabriel et al., 1976a, b).

The subjects in each group were chosen by pairwise matching on the basis of number of sessions prior to the criterion of original learning. This was done by pairing each member of the overtrained group with a member of the criterion group having an identical or nearly identical training score. Scores were considered nearly identical when they differed by one unit. With this procedure, it was possible to obtain nine matched pairs, such that the mean training score (1.62) associated with the criterion group was identical to the mean associated with the overtrained group. The matching procedure was carried out without knowledge of reversal scores.

\section{RESULTS AND DISCUSSION}

A t test for matched groups was computed on discrimination scores (percent responses to CS+ minus percent responses to $\mathrm{CS}-$ ) obtained in the fifth session of reversal. The mean discrimination score obtained from the group trained to criterion was $12.1 \%$ and the mean for the overtrained group was $45.0 \%$. The difference was significant $[t(8 \mathrm{df})=3.35, \mathrm{p}<.01]$, indicating a greater magnitude of discrimination appropriate to reversal in the overtrained group, relative to the group trained to criterion. The outcome indicates that the 
ORE is an effect which occurs in acoustically cued discriminative avoidance learning.

Despite the considerable number of theories which have been formulated to account for the ORE, there is at present little consensus among workers regarding the underlying basis of the effect.

A recent study has shown that neurons of the cerebral cortex show discriminative electrical activity in early stages of differential conditioning. Neuronal discrimination at the cortical level is reduced or absent during performance of the well-learned behavioral discrimination. However, thalamic neurons show discrimination only when the behavioral discrimination is well learned (Gabriel, Miller, \& Saltwick, 1976a). These findings suggest the possibility that rate of reversal learning may be critically dependent upon the structures which show discriminative activity when reversal training is initiated. Thus, the investigation of electrophysiological correlates of conditioning and reversal would seem a potentially fruitful approach to the theoretical problems posed by the ORE.

\section{REFERENCES}

Brogden, W. J., \& Culler, E. A. Device for motor conditioning of small animals. Science, 1936, 83; 269.

DENNY, M. R. Elicitation theory applied to an analysis of the overlearning reversal effect. In J. H. Reynierse (Ed.), Current issues in animal learning. New York: Academic Press, 1970.

Gabriel, M., Miller, J. D., \& Saltwick, S. E. Unit activity in anterior cingulate cortex and anteroventral thalamus of the rabbit during differential conditioning and reversal. Journal of Comparative and Physiological Psychology, 1977, 91, 423-433. (a)

Gabriel, M., Miller, J. D., \& Saltwick, S. E. Multipleunit activity of the rabbit medial geniculate nucleus in conditioning, extinction, and reversal. Physiological Psychology, 1976, 4, 124-134. (b)

Hall, G. Transfer effects produced by overtraining in the rat. Journal of Comparative and Physiological Psychology, 1974, 87, 938-944.
Lovejoy, E. Analysis of the overlearning reversal effect. Psychological Review, 1966, 73, 87-103.

Mackintosh, N. J. The psychology of animal learning. London: Academic Press, 1974.

Mandler, J. M. The effect of overtraining on the use of positive and negative stimuli in reversal and transfer. Journal of Comparative and Physiological Psychology, 1968, 66, 110-115.

PAUL, C. Effects of overlearning upon single habit reversal in rats. Psychological Bulletin, 1965, 63, 65-72.

REID, L. S. The development of noncontinuity behavior through continuity learning. Journal of Experimental Psychology, 1953, 46, 107-112.

SIEGEL, S. Overtraining and transfer processes. Journal of Comparative and Physiological Psychology, 1967, 64, 471-477.

SPERLING, S. E. Reversal learning and resistance to extinction: A review of the rat literature. Psychological Bulletin, 1965, 63, 281-297.

Sutherland, N. S., \& Mackintosh, N. J. Mechanisms of animal discrimination learning. New York: Academic Press, 1971.

\section{NOTE}

1. Rabbits that did not meet a criterion of discrimination appropriate to the reversal problem after five sessions of training were given 240 trials with the CS- each day until they met a criterion of extinction. After extinction, each subject was continued in reversal training. The interpolated extinction procedure was adopted to facilitate reversal because of the electrophysiological aspects of the experiment. Different numbers of subjects received extinction in the two groups; thus, group comparisons based on data of reversal sessions after the fifth session were precluded. It is of interest to note that eight of the nine subjects trained to criterion in acquisition failed to meet our criterion on the reversed discrimination after five reversal sessions, and were consequently given interpolated extinction. Only five of the nine overtrained subjects required interpolated extinction. The difference between these proportions was not significant, yet the direction of the differences was compatible with an ORE.

(Received for publication October 26, 1976.) 